Article

\title{
Improvement Effect of Green Lubricants on the Tribological and Mechanical Performance of 4140 Steel
}

\author{
María T. Hernández-Sierra ${ }^{1}{ }^{1}$, Micael G. Bravo-Sánchez ${ }^{1}$, José E. Báez ${ }^{2}$, \\ Luis D. Aguilera-Camacho ${ }^{1}$, J. Santos García-Miranda 1,*(D) and Karla J. Moreno ${ }^{1} \mathbb{D}$ \\ 1 Tecnológico Nacional de México en Celaya, Apartado Postal 57, 38010-Celaya, Guanajuato, Mexico; \\ tere.mths@hotmail.com (M.T.H.-S.); gerardo.bravo@itcelaya.edu.mx (M.G.B.-S.); \\ daniel.aguilera@itcelaya.edu.mx (L.D.A.-C.); karla.moreno@itcelaya.edu.mx (K.J.M.) \\ 2 Facultad de Química, Universidad de Guanajuato, Noria Alta S/N, 36050-Guanajuato, Guanajuato, Mexico; \\ jebaez14@yahoo.com.mx \\ * Correspondence: santos.garcia@itcelaya.edu.mx; Tel.: +52-461-611-7575; Fax: +52-461-611-7878
}

Received: 17 October 2019; Accepted: 12 November 2019; Published: 15 November 2019

Featured Application: In this work, the effect that bio-based lubricants have on the tribological and hardness properties of a mechanical system was studied for extending their industrial utilization. The results showed that Castor oil has potential application in the metal-mechanic industry as lubricant in fine blanking and wire drawing processes, as well as in gear transmissions systems.

\begin{abstract}
Although much has been learned and investigated about environmentally friendly lubricants in recent years, several issues remain critical to their use in specific applications. A key point that could be limiting their utilization is that the effect of green lubricants on the tribological and mechanical properties of the elements has not been thoroughly studied since such attributes determine their performance in industrial applications. For this reason, in this research, the effect of green lubrication on the tribological and hardness properties of AISI 4140 steel was studied. The performance of three bio-based lubricants was studied and compared to that of five of the most representative lubricants. First, the lubricants were chemically and physically characterized. Then, the effect of each lubricant on the friction and wear behavior of the system was analyzed by kinetic friction coefficient, wear rate calculations, and microhardness measurements. In general, the bio-based lubricants exhibited the lowest values of friction and wear. Further the mechanical properties of the systems lubricated by these lubricants were not affected or were affected to a lesser degree.
\end{abstract}

Keywords: bio-lubricants; environment-friendly lubrication; lubrication regime; microhardness; tribology

\section{Introduction}

The study and development of efficient and effective lubricants continue to be a focus for scientists, industries, and governments, since lubricants are substances that remain between surfaces in relative motion, mainly to reduce friction and wear [1-5]. Their use affects the efficiency of machinery, energy consumption, the local and global economy, and even the preservation of the environment $[1,2,5]$. Green tribology is a recent focus of tribology, which involves the classic challenges of tribology: to reduce friction and wear, but with an environmentalist approach [5]. Utilizing natural and biodegradable lubricants are two of the basic principles of green tribology that promote the use of green lubricants to prevent environmental pollution [5]. 
Green lubricants exhibit low toxicity, excellent biodegradability, and, usually, they are derived from natural vegetable oils [2,5]. The most commonly employed natural oils for producing bio-based lubricants are rapeseed, sunflower, canola, soybean, palm, coconut, and castor oil, to name a few [1,2,5-8]. Generally, vegetable oils have excellent lubricating properties, and they also present high viscosity indexes (VI) and high flash points [2,5,8]. Although natural oils have some limitations, such as poor cold flow properties and oxidation stability, such properties can be improved by chemical modifications (transesterification, hydrogenation, epoxidation, etc.) or by the incorporation of additives (anti-wear, anti-oxidation, friction modifiers, etc.) [2,9].

Current advances in green lubrication have been based on improving the physical and chemical properties of vegetable oils-for instance, the study of Xu et al. (2019) [10], who improved the dynamic viscosity, thermal stability, and oxidation stability of rapeseed and soybean oils by adding Pentaerythritol rosin ester. On the other hand, the enhancement of the friction response of some natural oils has been made principally by the addition of nanoparticles into the oils. One example is the investigation of Taha-Tijerina et al. (2019) [11], in which the authors improved the friction properties of soybean, sunflower, and corn oil by adding $\mathrm{SiO}_{2}$ nanoparticles, thereby enhancing the friction coefficient from $10 \%$ to $26 \%$. Castor oil has been one of the most valuable vegetable oils for lubricating applications. Recently, Zheng et al. (2018) [12] prepared an ecological ricinoleic acid based ionic liquid and studied its performance as an additive in glycerol solutions. They found a remarkable improvement in the anticorrosion and lubricating performance of the green lubricant. Yu et al. (2019) [13] instead enhanced the friction and adhesive wear response of Castor oil by adding $\mathrm{MoS}_{2}$ nanoparticles.

The previous research related to green lubricants shows the great progress that has been made in improving the friction and wear of vegetable oils as lubricants, as well as the formulation of more efficient bio-lubricants. However, as tribology also encompasses all the aspects of the interacting surfaces, it is important to characterize the surfaces of the lubricated contacts to understand their mechanisms of friction, wear, and lubrication [8]. Surface characterization by surface roughness and hardness measurements provides valuable complementary knowledge about the efficiency of the lubricated contact. Nevertheless, in the tribological performance research of green lubricants, hardness has been set aside, and this could be a crucial avenue to expand their applications.

Based on the above, in this study, the effect that green lubrication has on the tribological and hardness properties of a mechanical system was investigated. For this purpose, three bio-based lubricants were studied, two of them using vegetable oil bases and mineral oil fractions and synthetic esters, and one using neat vegetable oil (Castor oil). The performance of the green lubricants was studied and compared with that of five of the most distinctive lubricants: water, seawater, nano-lubricant, mineral oil, and synthetic oil. This study first consisted in the evaluation of the physical properties and characterization by FTIR spectroscopy of the lubricants. Then, the lubrication performance of the lubricants was evaluated by sliding contact experiments in a pin-on-disk configuration. For this purpose, a system of AISI 4140 steel against alumina $\left(\mathrm{Al}_{2} \mathrm{O}_{3}\right)$ was selected, since the AISI 4140 alloy is one of the most used steels for a wide variety of components and has high hardenability, toughness, and wear resistance [14]. On the other hand, $\mathrm{Al}_{2} \mathrm{O}_{3}$ is one of the most versatile hard ceramics and exhibits good strength, low thermal expansion, and high wear resistance [15]. Both materials are employed as tribological components in several industries, ranging from aerospace to automotive $[14,15]$. The lubrication regimes were determined, and the results were compared with the experimental results. The influence of each lubricant on the friction and wear features of the $4140 / \mathrm{Al}_{2} \mathrm{O}_{3}$ system was analyzed by the kinetic friction coefficient, wear rate, and micro-indentations of the hardness on the worn area. 


\section{Materials and Methods}

\subsection{Lubricants}

Table 1 catalogs the analyzed lubricants of the present study. It can be noted that the first five lubricants enclose the main types of lubricants utilized in general applications, while the last three include two of the main green lubricant formulations and one of the most advantageous vegetable oils for lubricant purposes in its pure form: castor oil. All the lubricants listed in Table 1 are commercially available and were used as acquired, except seawater (L2). Seawater was obtained by dissolving an artificial salt mixture similar in composition to the dissolved salts in ocean water (S9883, Sigma-Aldrich) in deionized water at a concentration of $40 \mathrm{~g} / \mathrm{L}$.

Table 1. Lubricants employed in the study.

\begin{tabular}{cl}
\hline Designation & \multicolumn{1}{c}{ Lubricating Medium } \\
\hline L1 & Water \\
L2 & Seawater \\
L3 & Graphite nanoparticles in water \\
L4 & Synthetic oil \\
L5 & Mineral oil \\
L6 & Natural oil with Mineral oil and *EP \\
L7 & Natural oil with Synthetic esters and *EP \\
L8 & Natural oil (Castor oil) \\
\hline & *EP: extreme pressure additives.
\end{tabular}

\subsection{Characterization of Lubricants}

\subsubsection{Physical Properties of Lubricants}

The satisfactory functionality of any lubricant in an application is defined by its chemical and physical properties. For that purpose, in this study, the mass density and viscosity of the lubricants were evaluated. The mass density was determined by the specific gravity bottle method, while the dynamic viscosity of lubricants was measured in a digital rotational viscometer Brookfield RVDV-II+Pro (Brookfield, MA, USA). The viscosity measurements were made as indicated in the equipment user manual. Each test was carried out for $5 \mathrm{~min}$, and then the viscosity value was recorded. The dynamic viscosity of lubricants L1 and L2 was obtained from the average values in the literature $[16,17]$ since their viscosity values are out of the measurement range of the equipment. In contact phenomena, the dynamic viscosity of a lubricant plays the most influential role; however, the kinematic viscosity is necessary to specify lubricants [8]. For that reason, the kinematic viscosity of the lubricants was calculated by dividing the dynamic viscosity by the density. It is important to mention that the temperature of the samples for density and viscosity measurements was maintained by using a thermal bath. In addition, for each measurement, three replications were performed, and the averages are presented.

\subsubsection{Chemical Characterization of the Lubricants}

The composition of a lubricant is essential because it determines the physical and chemical properties that will affect its operating performance. In that sense, to elucidate the general composition of lubricants, Attenuated Total Reflectance Fourier Transform Infrared spectroscopy (ATR-FTIR) analyses were performed. The spectra were recorded as the $\%$ transmittance in a range of $4000-650 \mathrm{~cm}^{-1}$ by using a Spectrum 100 Perkin Elmer spectrometer (Perkin Elmer, MA, USA) with an ATR module of ZnSe. The ATR-FTIR spectra were acquired after a few drops of each lubricant were placed on a cleaned ATR plate and performing four scans with a resolution of $4.0 \mathrm{~cm}^{-1}$. 


\subsection{Evaluation of the Effect of Lubricants on the Lubrication Regime, Friction, and Wear}

\subsubsection{Lubrication Regime Estimation}

A general approach to estimate the friction and wear behavior of a lubricating system is to determine the lubrication regime in which the system will operate: boundary, mixed, or hydrodynamic/elastohydrodynamic lubrication. These regimes are strongly dependent on the properties of lubricants. Each regime predicts different behavior, which can produce high or low friction-even mild or severe wear. In boundary lubrication, high friction and wear usually occur because the lubricant film is so thin that it allows larger contact between the surfaces. Contrarily, in hydrodynamic/elastohydrodynamic lubrication, the lubricant film is thick enough to eliminate the direct contact, thus reducing wear and friction. Mixed lubrication is a combination of the two previous modes, where the lubricant film is thicker to separate the surfaces, but there is still slight contact that could produce friction and wear. To deepen the characteristics of each lubrication regime, different studies $[3,4,8]$ can be consulted.

Knowing the minimum film thickness $\left(h_{\text {min }}\right)$, a specific type of lubrication can be determined by calculating the lambda ratio $(\lambda)$ or the film parameter. The boundary lubrication condition can be expected when $\lambda<1$, mixed when $1<\lambda<3$, and hydrodynamic/elastohydrodynamic lubrication can be expected when $\lambda>3$. The film parameter can be calculated by Equation (1), where $\sigma_{1}$ and $\sigma_{2}$ are the surface roughnesses of Elements 1 and 2, respectively:

$$
\lambda=\frac{h_{\min }}{\sqrt{\sigma_{1}^{2}+\sigma_{2}^{2}}} .
$$

The minimum film thickness can be obtained by the equations of B. J. Hamrock and D. Dowson [18] for point contacts, as applied in [6]. For that purpose, the values of the pressure-viscosity coefficient $\left(\alpha_{p}\right)$ of the lubricants are required. In this work, the pressure-viscosity coefficient was calculated following the procedure reported earlier in appendix A in [6]. In the previous work, the estimation of the $\alpha_{p}$ was obtained from the properties of the lubricants by the methodology of W. G. Johnston [19]. This procedure first involves determination of the density and viscosity properties of a liquid lubricant at ambient pressure at two or more different temperatures. Then, the coefficients of compressibility $(\beta)$ and thermal expansivity $\left(\alpha_{T}\right)$, as well as the slope of the graph of the logarithm of viscosity vs. the reciprocal of temperature $\left(S_{V / T}\right)$ are determined from these properties to obtain the $\alpha_{p}$ by the relationship expressed in Equation (2):

$$
\alpha_{p}=-\frac{\beta\left(S_{V / T}\right)}{2 \alpha_{T} T^{2}}
$$

Nevertheless, as an exception to this method, in the present study, the coefficient of compressibility $(\beta)$ was calculated from the reciprocal of the isothermal secant bulk modulus $\left(\beta_{T, S}\right)$ expressed in Equation (3) for any specific fluid and constant temperature conditions [20]. In Equation (3), $v$ represents the kinematic viscosity at atmospheric pressure $(\mathrm{cSt}), T$ the temperature $\left({ }^{\circ} \mathrm{C}\right)$, and $P$ the pressure (bar):

$$
\beta_{T, S}=[1.30+0.15 \log (v)]\left[10^{0.0023(20-T)}\right] \times 10^{4}+5.6 P .
$$

\subsubsection{Sliding Friction and Wear Evaluation}

Sliding friction experiments were accomplished by a pin-on-disk configuration, which is commonly used to analyze the wear of a great variety of materials [6]. In this configuration, a pin (usually a ball) comes into contact with the disk surface that is attached to the equipment's cup. Then, the disk starts to rotate, generating friction and causing a ring-shaped mark on the surface of the steel due to wear. The general configuration of friction experiments in a pin-on-disk apparatus is depicted in Figure 1a. Further, Figure 1b,c shows the CSM Tribometer (CSM Instruments, Peseux, Switzerland) 
employed and the configuration for the lubricated tests. In this work, disks of AISI 4140 annealed steel, whose composition has been previously reported [7], were prepared as in [6,7], thus obtaining a final arithmetic average of the roughness profile (Ra) of $0.04 \mu \mathrm{m}$. Commercial balls of alumina $\left(\mathrm{Al}_{2} \mathrm{O}_{3}\right)$, whose diameter and surface roughnesses were $6 \mathrm{~mm}$ and $0.03 \mu \mathrm{m}$ in $\mathrm{Ra}$, respectively, were used as the stationary elements.
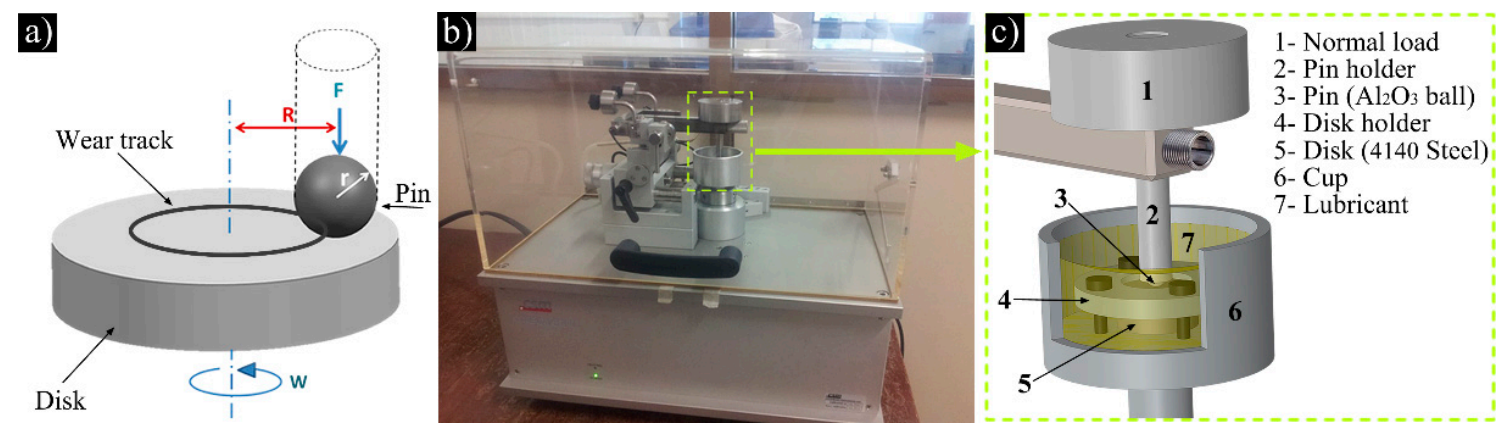

Figure 1. The schematization of friction and wear experiments: (a) general configuration for pin-on-disk tests, (b) the tribometer employed, and (c) the configuration for lubricated tests.

Before testing and measuring, the elements were carefully cleaned with hexane. For the experiments, the pin was settled at a radius of $2 \mathrm{~mm}$ from the center of the disk, and the normal load applied through this was $5 \mathrm{~N}$. The disk was rotated at $5 \mathrm{~cm} / \mathrm{s}$ with a total distance of $1000 \mathrm{~m}$. Thirty milliliters of each lubricant were placed into the cup immediately before the tests, thereby ensuring fully lubricated conditions. During the experiments, the kinetic friction coefficient $\left(\mu_{\mathrm{k}}\right)$ was recorded by Tribox 4.5.R software (CSM Instruments, Peseux, Switzerland), and the average is presented.

The wear of the steel samples and the contact profilometry were evaluated by optical microscopy using a Carl Zeiss Axio Imager.A1m microscope (ZEISS, Göttingen, Germany) and a Mitutoyo SJ-400 profilometer (Mitutoyo, Kanagawa, Japan), respectively. The wear rate $(K)$ was calculated by Equation (4), where $R$ represents the wear track radius, $A$ is the area of the wear track profiles calculated by integration, $F$ is the normal load, and $S$ is the sliding distance:

$$
K=\frac{2 \pi R A}{F S} .
$$

\subsubsection{Microhardness Evaluation}

Additionally, to deepen the evaluation of the damage caused by the lubricants in the mechanical elements, the hardness of the steel samples was also studied. The hardness measurements on the worn surfaces were performed with a Vickers-Knoop micro-indenter Auto SMVK-1000ZS (Metrotec, Gipuzkoa, Spain). Nearly 20 micro-indentations of hardness were made around the wear track by applying a load of $1.96 \mathrm{~N}$ ( $200 \mathrm{gr}$ ) for $15 \mathrm{~s}$. The average values are presented.

\section{Results}

\subsection{Characterization of Lubricants}

\subsubsection{Physical Properties of Lubricants}

The mass density $(\rho)$, as well as the dynamic $(\mu)$ and kinematic $(v)$ viscosity of the lubricants employed in the present study, are listed in Table 2. In general, it can be seen that the lubricants have a wide variety of viscosity values. The water-based lubricants (L1, L2, and L3) have the lowest viscosities, while the synthetic oil (L4) has the highest one-more than a thousand times higher. Otherwise, all the bio-based lubricants (L6, L7, and L8) presented similar viscosity values. In the following sections, 
the effects of these properties on the friction and wear behavior of the AISI 4140 steel- $-\mathrm{Al}_{2} \mathrm{O}_{3}$ system will be analyzed.

Table 2. Mass density $(\rho)$, dynamic viscosity $(\mu)$, and kinematic viscosity $(v)$ of lubricants.

\begin{tabular}{ccccccccc}
\hline \multirow{2}{*}{ Property at $\mathbf{2 5}{ }^{\circ} \mathbf{C}$} & \multicolumn{8}{c}{ Lubricant } \\
\cline { 2 - 9 } & L1 & L2 & L3 & L4 & L5 & L6 & L7 & L8 \\
\hline $\boldsymbol{\rho}\left(\mathrm{Kg} / \mathrm{m}^{3}\right)$ & 997 & 1027 & 1035 & 976 & 914 & 1126 & 1159 & 961 \\
$\mu\left(\times 10^{-3} \mathrm{~Pa} \cdot \mathrm{s}\right)$ & 0.89 & 0.98 & 53 & 1093 & 260 & 798 & 883 & 691 \\
$\boldsymbol{v}\left(\times 10^{-6} \mathrm{~m}^{2} / \mathrm{s}\right)$ & 0.89 & 0.95 & 51 & 1120 & 285 & 709 & 762 & 719 \\
\hline
\end{tabular}

\subsubsection{Chemical Characterization of Lubricants}

The nature of these lubricants is presented by the ATR-FTIR study, as follows. Figure 2 shows the ATR-FTIR spectra of the water-based lubricants (L1, L2, and L3). As it can be observed from this figure, the base spectra of the three lubricants show traditional large and intense bands of water. A strong and broad peak at around $3300 \mathrm{~cm}^{-1}$ due to the stretching vibrations of $\mathrm{O}-\mathrm{H}$, an intense peak at around $1630 \mathrm{~cm}^{-1}$ related to the $\mathrm{O}-\mathrm{H}-\mathrm{O}$ scissors bending vibrations, and a small band at $2120 \mathrm{~cm}^{-1}$ resulting from the coupling of the scissors bending signal and a broad liberation band can be observed in these spectra [21]. Despite these strong bands of water, it is possible to identify in this figure that the bands in the saline water (L2) spectrum have shifted slightly to the left, likely due to the presence of salts in water. On the other hand, the L3 spectrum shows additional bands at around $1394 \mathrm{~cm}^{-1}$ and $1060 \mathrm{~cm}^{-1}$ assigned to the $\mathrm{C}-\mathrm{OH}$ and $\mathrm{C}-\mathrm{O}$ stretching vibrations, respectively, which, along with others, overlap the bands at about 3410,1720 , and $1620 \mathrm{~cm}^{-1}$, correspond to the nature of graphite [22,23].

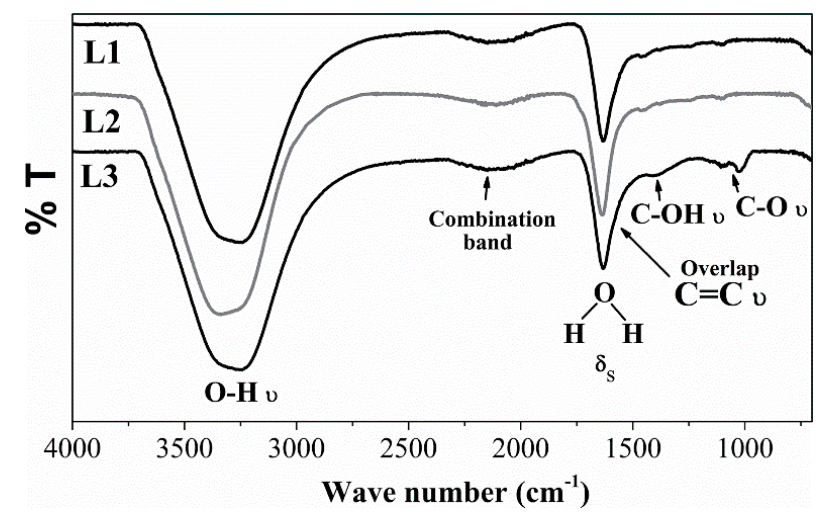

Figure 2. Attenuated Total Reflectance Fourier Transform Infrared spectroscopy (ATR-FTIR) spectra of water-based lubricants.

The ATR-FTIR spectra of the synthetic (L4) and mineral oils (L5) are shown in Figure 3. It can be seen that the spectrum of L4 exhibits the signals of polydimethylsiloxane. It has small peaks at about 2963 and $1410 \mathrm{~cm}^{-1}$ due to asymmetric stretching and bending vibrations of the $\mathrm{CH}_{3}$ group, an intense peak at $1259 \mathrm{~cm}^{-1}$ associated to the $\mathrm{CH}_{3}$ symmetric bending vibration in $\mathrm{Si}\left(\mathrm{CH}_{3}\right)_{2}$, a strong band between 1100 and $1000 \mathrm{~cm}^{-1}$ as a result of $\mathrm{Si}-\mathrm{O}$ stretching vibrations in $\mathrm{Si}-\mathrm{O}-\mathrm{Si}$, and peaks at 865 and $784 \mathrm{~cm}^{-1}$ attributed to the rocking vibration of $\mathrm{CH}_{3}$ around $\mathrm{Si}-\mathrm{C}$ and the stretching vibration of $\mathrm{Si}-\mathrm{C}$, respectively [24,25]. As the signal located between 1100 and $1000 \mathrm{~cm}^{-1}$ unfolds into two components, it is inferred that the oil is of a long-chain length and, therefore, a high molecular weight, which was reflected in its high viscosity [24]. On the other hand, the L5 spectrum shows strong bands at around 2922, 2851, 1459, and $1374 \mathrm{~cm}^{-1}$ corresponding to the stretching and bending vibrations of hydrocarbons $\mathrm{CH}_{2}$ and $\mathrm{CH}_{3}$, and a small peak at $721 \mathrm{~cm}^{-1}$ caused by the vibration of $\mathrm{CH}_{2}$ that is characteristic of the degree of the refining process of a mineral oil [26]. 


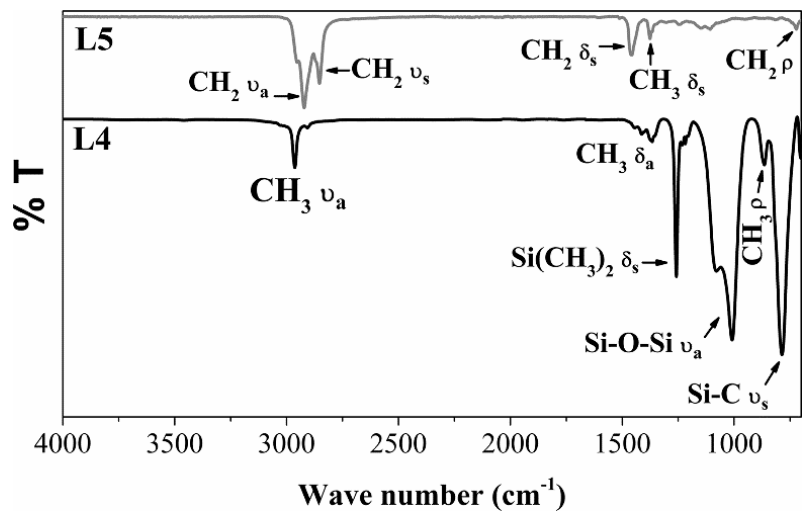

Figure 3. ATR-FTIR spectra of synthetic (L4) and mineral (L5) oils.

The ATR-FTIR spectra of the natural-based lubricants (L6, L7, and L8) are shown in Figure 4. Natural oils are triglyceride esters of fatty acids, and this triglyceride nature can be corroborated by the intense bands at around $1743 \mathrm{~cm}^{-1}$ that is the result of the stretching vibration of the ester group $\mathrm{C}=\mathrm{O}$. These spectra also show strong signals at 2924 and $2855 \mathrm{~cm}^{-1}$ corresponding to $\mathrm{CH}_{2}$ asymmetric and symmetric stretching vibrations, respectively. Additionally, each lubricant exhibits a different fingerprint region due to the type of natural oil and the other components present in the lubricants. For example, the peaks at 1460 and $1370 \mathrm{~cm}^{-1}$ corresponding to symmetric bending vibrations of $\mathrm{CH}_{2}$ and $\mathrm{CH}_{3}$ groups, are probably higher in L6 because it also contains a fraction of mineral oil. On the other hand, it is important to note the broad band at about $3430 \mathrm{~cm}^{-1}$ belonging to vibrations of the $\mathrm{O}-\mathrm{H}$ group in L8, which is a characteristic of Castor oil.

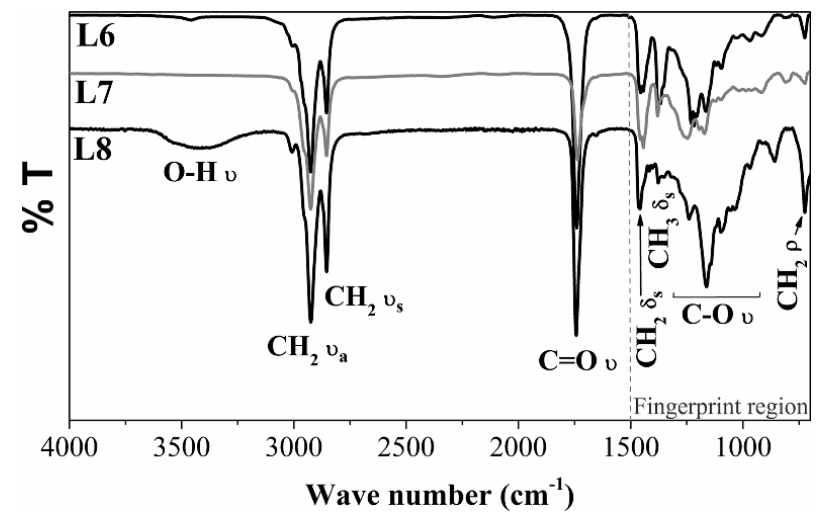

Figure 4. ATR-FTIR spectra of natural-based lubricants.

\subsection{Effect of Lubricants on the Lubrication Regime, Friction, and Wear}

\subsubsection{Lubrication Regime Estimation}

The lubrication regimes are summarized in Table 3. For these results, the dimensionless parameters of load $(W)$ and ellipticity $(k)$ were $2.10 \times 10^{-6}$ and 1 , respectively. It can be seen that the systems lubricated with water-based lubricants (L1, L2, and L3) exhibited the lowest film thicknesses $\left(h_{\text {min }}\right)$, which would make the systems operate in extreme Boundary conditions. Higher film thicknesses can be observed in systems lubricated with the synthetic (L4) and mineral (L5) oils. However, the same regime as water-based lubricants was found. On the other hand, all the bio-based lubricants (L6, L7, and L8) were estimated to operate in the Mixed lubricating regime with similar film thickness values between them. When analyzing these results, it can be observed that although the synthetic lubricant (L4) exhibited the highest viscosity, its low pressure-viscosity coefficient $\left(\alpha_{p}\right)$ did not allow it to form a thicker lubricating film. The same result was obtained with water-based lubricants (L1, L2, and L3), 
which have low viscosity and a low pressure-viscosity coefficient $\left(\alpha_{p}\right)$. However, it was observed that the bio-based lubricants (L6, L7, and L8), which have both high viscosity and a high pressure-viscosity coefficient $\left(\alpha_{p}\right)$, exhibited the thickest lubricating film. This behavior coincides with that suggested in [4] for achieving thick lubricating films.

Table 3. Estimation of the lubrication regime for the different lubricated systems.

\begin{tabular}{ccccccc}
\hline Lubricant & $\mathbf{U}$ & $\boldsymbol{\alpha}_{\boldsymbol{p}}\left(\mathbf{P a}^{-\mathbf{1}}\right)$ & $\mathrm{G}$ & $\boldsymbol{h}_{\min }(\mathbf{n m})$ & $\boldsymbol{\lambda}_{\min }$ & Lubrication Regime \\
\hline L1 & $2.81 \times 10^{-14}$ & $2.32 \times 10^{-8}$ & 6135 & 0.6 & 0.01 & Boundary \\
L2 & $3.08 \times 10^{-14}$ & $2.10 \times 10^{-8}$ & 5542 & 0.6 & 0.01 & Boundary \\
L3 & $1.67 \times 10^{-12}$ & $2.57 \times 10^{-8}$ & 6777 & 10.3 & 0.21 & Boundary \\
L4 & $3.45 \times 10^{-11}$ & $0.91 \times 10^{-8}$ & 2392 & 48.5 & 0.97 & Boundary \\
L5 & $8.20 \times 10^{-12}$ & $1.81 \times 10^{-8}$ & 4787 & 25.7 & 0.51 & Boundary \\
L6 & $2.52 \times 10^{-11}$ & $4.30 \times 10^{-8}$ & 11369 & 84.1 & 1.68 & Mixed \\
L7 & $2.79 \times 10^{-11}$ & $3.63 \times 10^{-8}$ & 9587 & 82.9 & 1.66 & Mixed \\
L8 & $2.18 \times 10^{-11}$ & $3.86 \times 10^{-8}$ & 10193 & 72.2 & 1.44 & Mixed \\
\hline
\end{tabular}

\subsubsection{Effect of Lubricants on Friction and Wear}

The effect of lubricants on the kinetic friction coefficient $\left(\mu_{k}\right)$ is graphed in Figure 5. In general, it can be seen that the bio-based lubricants produced the lowest friction coefficients; friction was reduced up to $82.2 \%$ with the neat Castor oil compared to the highest value achieved with water (L1) as a lubricant $\left(\mu_{k}=0.45\right)$. It can be observed that the water-based lubricants (L1, L2, and L3) caused the highest friction of the system. This behavior was expected since the water-based lubricants were estimated to operate in boundary lubrication and to achieve the lowest film thicknesses. This caused a higher number of asperities to come into contact, and, therefore, the force necessary to allow the sliding was greater. The synthetic oil (L4), despite having higher viscosity and lubricant film thickness, produced a higher friction coefficient than the lubricant made of water with graphite nanoparticles (L3) and the mineral oil (L5). Even though mineral oil (L5) worked under boundary conditions, it was observed to generate similar friction to the bio-based lubricant with synthetic esters (L7) and even less than that with mineral oil (L6).

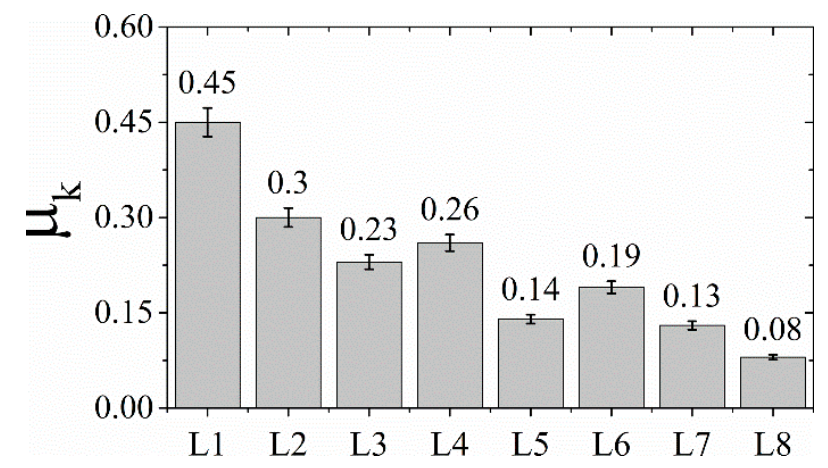

Figure 5. Effect of lubricants on the average kinetic friction coefficient $\left(\mu_{\mathrm{k}}\right)$.

Figure 6 exhibits optical micrographs of the worn surfaces and the wear track profiles of the steel samples tested with each lubricant. It can be noticed that the samples lubricated with water-based lubricants (L1 and L2) experienced very similar abrasive wear, presenting different wear phenomena like grooves, burnishes, and micro-pitting, mainly. Moreover, their wear track profiles exhibited accumulated material at the ends of the wear track (pile-up). However, on the sample lubricated with graphite nanoparticles in water (L3), bumps and some grooves characteristics of adhesive and abrasive wear can be observed. Practically speaking, the steel samples lubricated with the synthetic lubricant (L4) were the most affected. They suffered abrasive wear that generated scratches and wedge-like wear, and, according to the wear profile, there was also adhered material at the center of the wear track. 
On the other hand, the mineral (L5) and bio-based lubricants (L6, L7, and L8) generated the lowest wear of the steel samples principally by abrasion. The optical micrographs of these samples exhibited burnishing, scratching, and polishing marks, while the profiles confirmed a slight plowing effect.
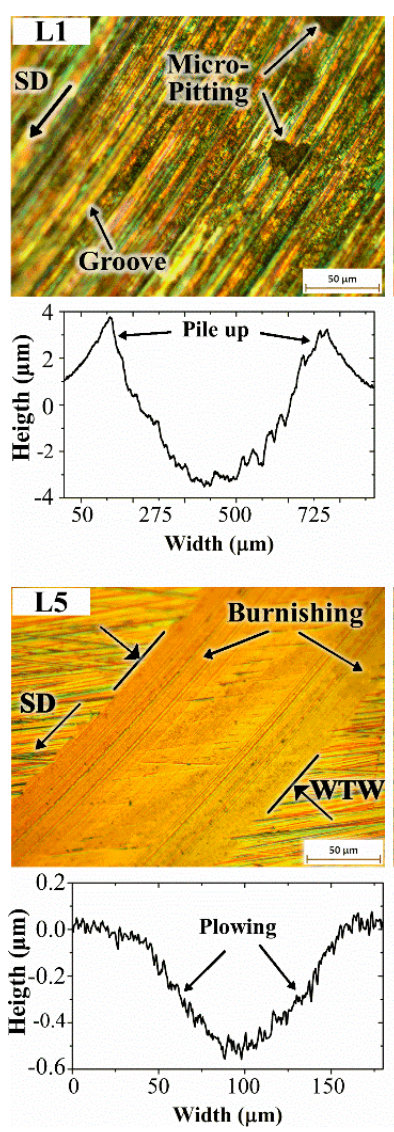
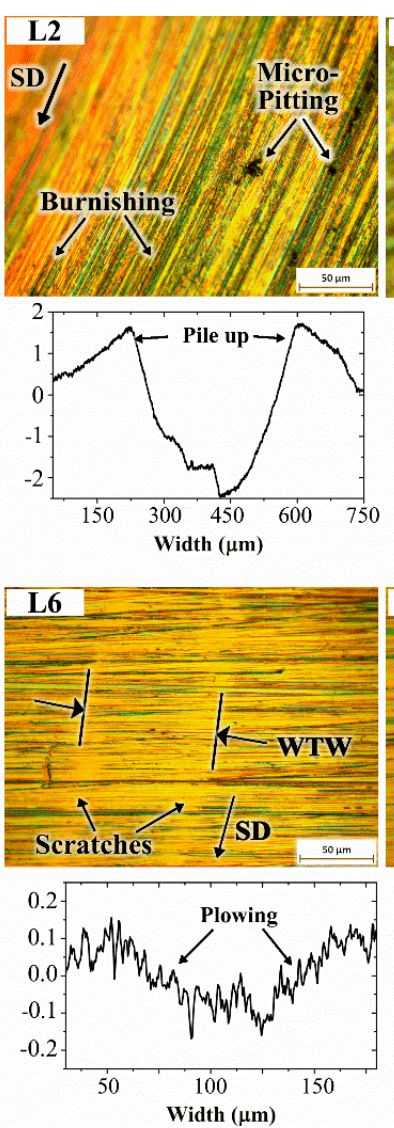
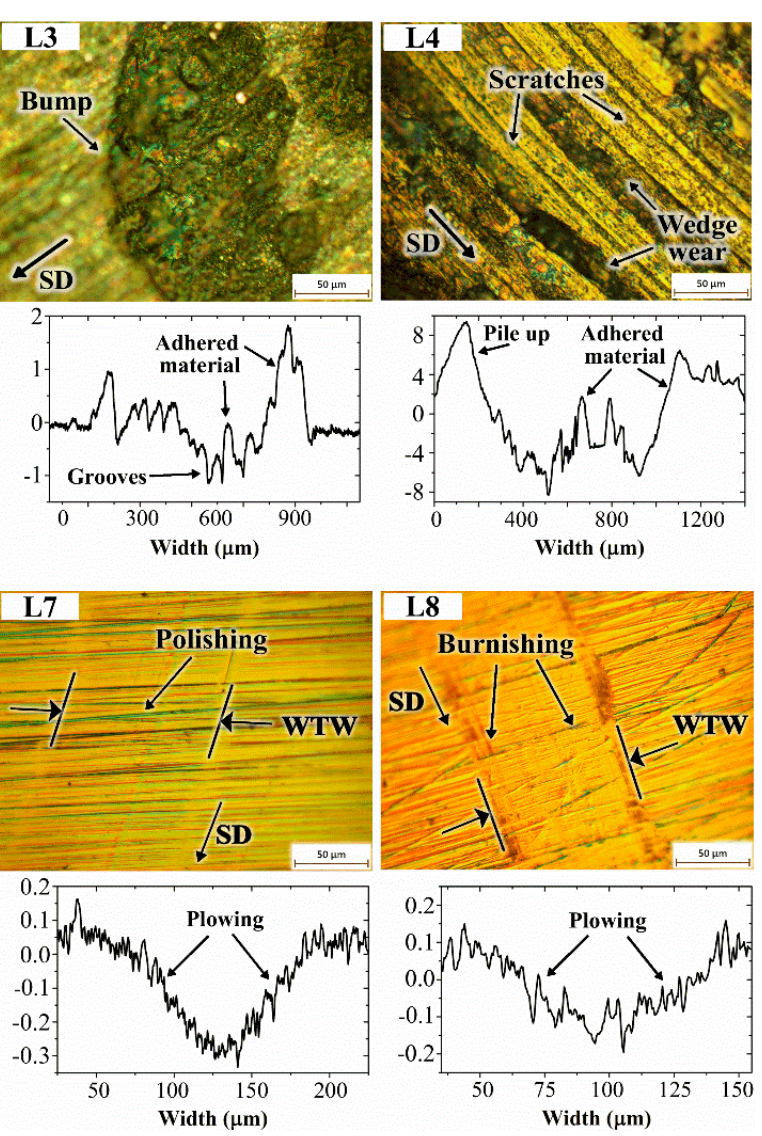

Figure 6. Worn surfaces micrographs at 500X (up) and wear track profiles (down) of the steel samples.

The observed damage of the steel was corroborated by computing the wear rate (see Figure 7). It can be seen in Figure 7 that the lowest wear rate values were achieved with all the bio-based lubricants (L6, L7, and L8). The wear rate obtained with L8 was up to $99.8 \%$ lower than that found with the synthetic lubricant $\mathrm{L} 4\left(K=2.3 \times 10^{-5} \mathrm{~mm}^{3} / \mathrm{Nm}\right)$.

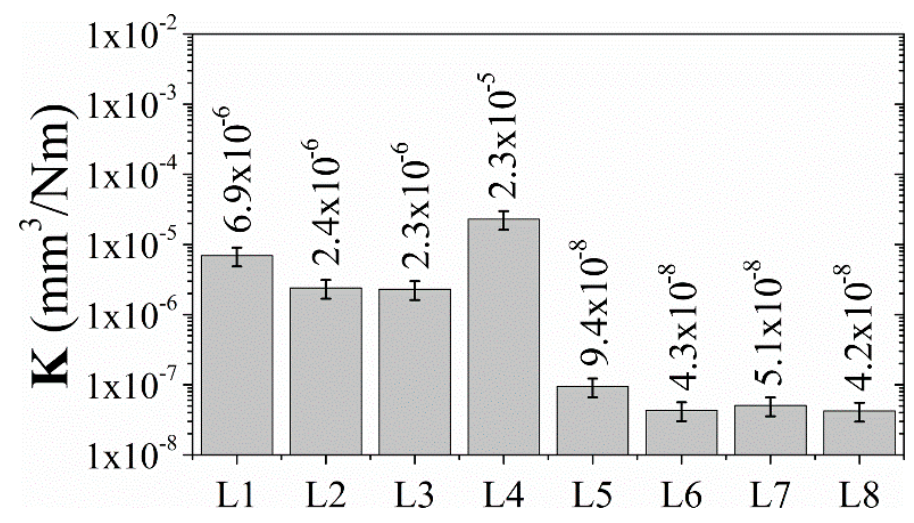

Figure 7. Effect of lubricants on the wear rate $(K)$ of the steel samples tested $(Y$-axis in logarithmic scale). 


\subsubsection{Effect of Lubricants on Microhardness}

In boundary lubricated systems (which were achieved with lubricants L1 to L5), mechanical effects can occur, and these affects can be reflected by a change in the hardness of the materials on the worn zone [3]. This phenomenon can affect the performance of the machinery because, if hardness changes, both friction and wear can increase. In this work, as the systems operated in boundary and mixed lubrication conditions, the microhardness on the worn zone of the steel was affected according to the lubricant employed, as can be observed in Figure 8. It can be seen in this figure that the microhardness of the samples lubricated with water-based lubricants (L1, L2, and L3) and the synthetic oil (L4) increased in relation to the initial substrate hardness. Specifically, the hardness of the sample lubricated with L4 increased up to $22.5 \%$. The opposite phenomenon occurred with the samples lubricated with mineral oil (L5) and bio-based oils L6 and L7, which showed a slight decrease in microhardness. It is important to note that the neat natural oil (L8) did not produce alterations in its substrate hardness, instead keeping its initial micro-hardness substrate value.

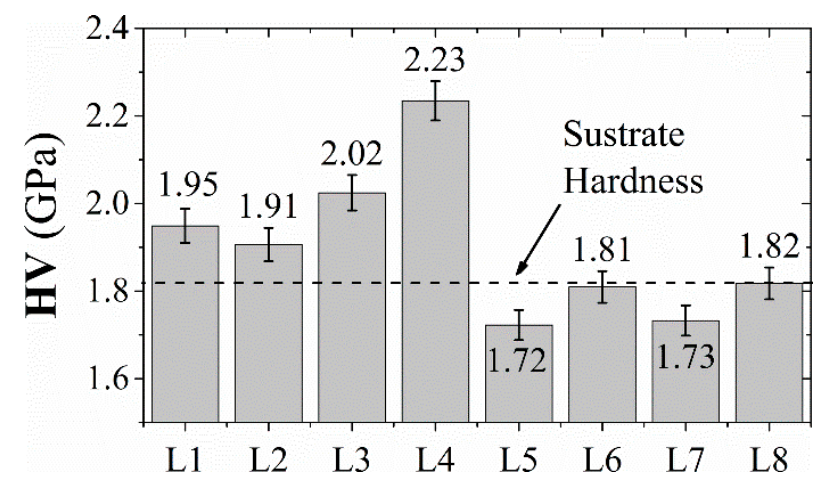

Figure 8. Influence of lubricants on the microhardness within the worn surfaces of the 4140 steel.

In order to deepen the change of hardness of the steel samples as an effect of the lubrication process, three representative samples were cut transversely, polished, and analyzed. Then, new measurements were made on the transverse plane, as illustrated in Figure 9. The first sample was the lubricated one with synthetic lubricant (L4), with the highest increase in hardness; the second used the natural-based oil with synthetic esters (L7), whose hardness decreased; and the third used the natural-based lubricant with mineral oil (L6), whose hardness was not affected. The hardness on the transverse planes, from the surfaces to the substrates, was graphed and can be observed in Figure 10. It can be seen in this figure that the change in the microhardness of the steel did not only occur near the worn surface but also affected a considerable distance of the bulk substrate. These distances indicate the intensity of damage (boundary layers) that the lubrication process produced on the material and are also an indication of the effectiveness of the lubricants. In this sense, it can be seen that the bio-based lubricant with synthetic esters (L7) affected up to $175 \mu \mathrm{m}$ of the material, the synthetic lubricant (L4) affected $350 \mu \mathrm{m}$, and the bio-based lubricant with mineral oil (L6) only affected the surface of the material. 

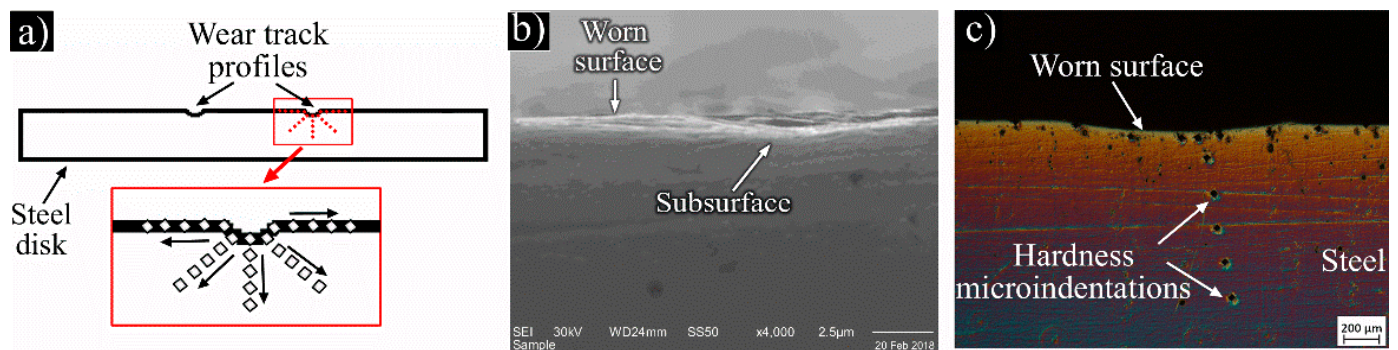

Figure 9. Hardness measurements on the transverse plane: (a) general schematization, (b) SEM, and (c) optical micrographs of the sample lubricated with L4. Note: the SEM micrograph was taken in a Jeol JSM-6510LV Scanning Electron Microscope.

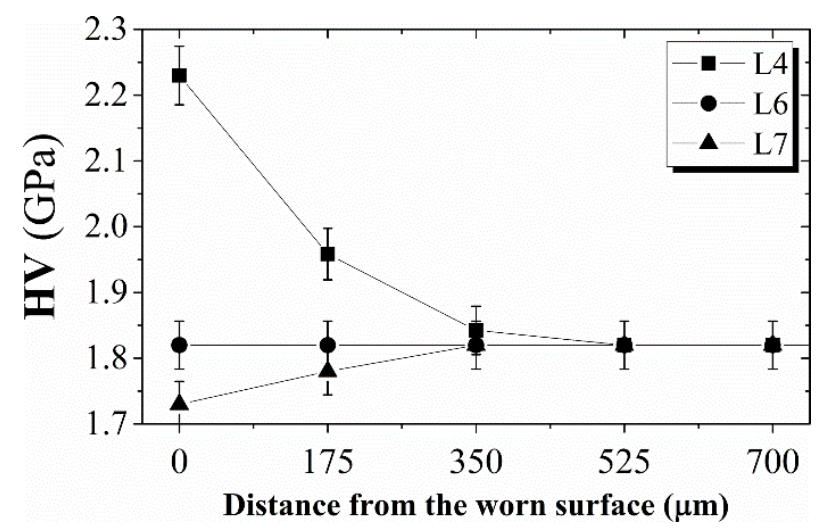

Figure 10. Influence of lubricants L4, L6, and L7 on the transverse hardness of AISI 4140 steel samples, from the worn surface to the substrate.

The increase in hardness exhibited on samples lubricated with water-based lubricants (L1, L2, and L3) and synthetic lubricant (L4) could be due to the severe plastic deformation that took place during the sliding process. This plastic deformation can be corroborated on one side by the subsurface layer on the sample lubricated with L4 (Figure 9b) formed by plastic deformation via friction. On the other hand, the decrease in hardness could be related to a microstructural change, similar to that observed in the same steel under severe wear conditions [6].

Considering the previous results, it can be observed that the best friction, wear, and hardness response of the studied system was observed under lubrication with all the bio-based lubricants (L6, L7, and L8), with the neat Castor oil (L8) being the best lubricant in all the experiments. An explanation for these behaviors could be the chemical nature of the base lubricant-the type of fatty acids, the carbon chain length, and the polarity of the natural oil [2]. Such characteristics define their chemical, physical, and lubricating properties. In this way, natural oils are mostly composed by triglycerides, which are tri-esters of fatty acids and glycerol. Such esters are, in general, polar long-chain molecules and exhibit a high degree of linearity and flexibility $[2,4,27]$. Those characteristics give lubricants better viscosity-temperature properties, relatively thinner lubricating film thicknesses, and lower friction compared to the ones with branched and rigid structures [2,4]. Moreover, their polar ester groups allow them to adhere to metal surfaces, thereby reducing friction and wear [28]. The difference in the performance of the three natural-based lubricants (L6, L7, and L8) may be due to, in the first instance, the type of seed oil, since L8 mainly consists of Castor oil, which has better viscosity and lubricity properties than most vegetable oils [2]. Secondly, the other components and additives in lubricants can also influence their performances because the more non-linear and non-flexibility molecules a lubricant contains, the more friction will be generated. One example is the natural lubricant with mineral oil (L6), which, according to a previous ${ }^{1} \mathrm{H}-\mathrm{NMR}$ study reported in [6], consists of non-linear mineral compounds and natural oil whose acrylic composition consists of oleic, linoleic, and linolenic fatty acids (commonly presented in greater volume in olive, canola, rapeseed, sunflower, and soybean 
oils [2]). Due to this composition, L6 could exhibit higher friction than L7, which consists of natural oil with synthetic esters (linear molecules of methyl oleate fatty acid), and L8, which consists of neat castor oil.

\section{Conclusions}

In this work, the effect of green lubrication on the tribological and hardness properties of a 4140 steel $/ \mathrm{Al}_{2} \mathrm{O}_{3}$ mechanical system was investigated and compared to that of five of the most typical lubricants. The main results are shown below:

- It was observed that bio-based lubricants created thicker lubricating films than the other analyzed lubricants due to their high viscosity and high pressure-viscosity coefficients.

- The bio-based lubricants exhibited the lowest friction values, reducing on average up to $50 \%$ in comparison to the other lubricants in this study.

- The bio-based lubricants exhibited the lowest wear with similar mechanisms of wear.

- Bio-lubrication almost entirely reduced the damage to the microhardness of steel.

- The best friction and wear response of the $4140 / \mathrm{Al}_{2} \mathrm{O}_{3}$ system was achieved under lubrication with neat castor oil (L8). The kinetic friction coefficient and wear rate were 0.08 and $4.3 \times 10^{-8}$ $\mathrm{mm}^{3} / \mathrm{Nm}$, respectively. Further, this lubricant did not modify the hardness of the steel sample.

For the above, the present investigation showed that green lubricants with vegetable oil bases have better lubrication and anti-wear capacities than other lubricants when lubricating hybrid (metal-ceramic) mechanical systems. Those characteristics indicate that these lubricants do not have any technical deficiencies as lubricants in engineering applications and make vegetable bases a good choice for the manufacture of green lubricants.

Author Contributions: Conceptualization, J.S.G.-M. and K.J.M.; Formal analysis, M.T.H.-S., L.D.A.-C., J.S.G.-M., and K.J.M.; Methodology, M.T.H.-S., M.G.B.-S., J.E.B., and L.D.A.-C.; Project administration, J.S.G.-M. and K.J.M.; Supervision, J.S.G.-M. and K.J.M.; Validation, J.S.G.-M. and K.J.M.; Writing-original draft, M.T.H.-S.; Writing-review and editing, K.J.M.

Funding: This research received no external funding.

Acknowledgments: The authors acknowledge the assistance of Tecnológico Nacional de México (TecNM). M.T. Hernández-Sierra thanks to Consejo Nacional de Ciencia y Tecnología (CONACYT) in Mexico for providing financial support for her doctoral studies.

Conflicts of Interest: The authors declare no conflict of interest.

\section{References}

1. Cai, M.R.; Guo, R.S.; Zhou, F.; Liu, W.M. Lubricating a bright future: Lubrication contribution to energy saving and low carbon emission. Sci. China Technol. Sci. 2013, 56, 2888-2913. [CrossRef]

2. Zainal, N.A.; Zulkifli, N.W.M.; Gulzar, M.; Masjuki, H.H. A review on the chemistry, production, and technological potential of biobased lubricants. Renew. Sustain. Energy Rev. 2018, 82, 80-102. [CrossRef]

3. Hamrock, B.J.; Schmid, S.R.; Jacobson, B.O. Fundamentals of Fluid Film Lubrication; Marcel Dekker Inc.: New York, NY, USA, 2004.

4. Gschwender, L.J.; Kramer, D.C.; Lok, B.K.; Sharma, S.K.; Snyder, C.E.; Sztenderowicz, M.L. Liquid lubricants and lubrication. In Modern Tribology Handbook; Bhushan, B., Ed.; CRC Press LLC: Boca Raton, FL, USA, 2001; Volume 1, pp. 361-382.

5. Nosonovsky, M.; Bhushan, B. Green tribology: Principles, research areas and challenges. Philos. Trans. R. Soc. A 2010, 368, 4677-4694. [CrossRef]

6. Hernández-Sierra, M.T.; Aguilera-Camacho, L.D.; Baez-García, J.E.; García-Miranda, J.S.; Moreno, K.J. Thermal stability and lubrication properties of biodegradable castor oil on AISI 4140 steel. Metals 2018, 8, 428. [CrossRef]

7. Hernández-Sierra, M.T.; Ortega-Álvarez, R.; Bravo-Sánchez, M.G.; Aguilera-Camacho, L.D.; García-Miranda, J.S.; Moreno, K.J. Tribological improvement of hardened and tempered AISI 4140 steel against $\mathrm{Al}_{2} \mathrm{O}_{3}$ by using bio-lubricant. MRS Adv. 2017, 2, 3873-3881. [CrossRef] 
8. Torbacke, M.; Rudolphi, Å.K.; Kassfeldt, E. Lubricants: Introduction to Properties and Performance; E. John Wiley \& Sons Ltd: West Sussex, UK, 2014.

9. Minami, I. Molecular Science of Lubricant Additives. Appl. Sci. 2017, 7, 445. [CrossRef]

10. Xu, Z.; Lou, W.; Zhao, G.; Zhang, M.; Hao, J.; Wang, X. Pentaerythritol rosin ester as an environmentally friendly multifunctional additive in vegetable oil-based lubricant. Tribol. Int. 2019, 135, 213-218. [CrossRef]

11. Taha-Tijerina, J.; Aviña, K.; Diabb, J.M. Tribological and thermal transport performance of $\mathrm{SiO}_{2}$-based natural lubricants. Lubricants 2019, 7, 71. [CrossRef]

12. Zheng, D.; Wang, X.; Zhang, M.; Liu, Z.; Ju, C. Anticorrosion and lubricating properties of a fully green lubricant. Tribol. Int. 2018, 130, 324-333. [CrossRef]

13. Yu, R.; Liu, J.; Zhou, Y. Experimental study on tribological property of $\mathrm{MoS}_{2}$ nanoparticle in castor oil. J. Tribol. 2019, 141, 102001. [CrossRef]

14. Lorenzo-Martín, C.; Ajayi, O.O. Rapid Surface hardening and enhanced tribological performance of 4140 steel by friction stir processing. Wear 2015, 332-333, 962-970. [CrossRef]

15. Suresh, S.; Venkatesan, K.; Natarajan, E.; Rajesh, J. Influence of tool rotational speed on the properties of friction stir spot welded AA7075-T6/ $\mathrm{Al}_{2} \mathrm{O}_{3}$ composite joint. Mater. Today-Proc. 2019. [CrossRef]

16. Kestin, J.; Sokolov, M.; Wakeham, W.A. Viscosity of liquid water in the range-SoC to $150{ }^{\circ}$ C. J. Phys. Chem. Ref. Data 1978, 7, 941-948. [CrossRef]

17. Sharqawy, M.H.; Lienhard, V.J.H.; Zubair, S.M. Thermophysical properties of seawater: A review of existing correlations and data. Desalin. Water Treat. 2010, 16, 354-380. [CrossRef]

18. Hamrock, B.J.; Dowson, D. Isothermal elastohydrodynamic lubrication of point contacts: Part 111—Fully flooded results. J. Tribol. 1977, 99, 264-275. [CrossRef]

19. Johnston, W.G. A method to calculate the pressure-viscosity coefficient from bulk properties of lubricants. ASLE Trans. 1981, 24, 232-238. [CrossRef]

20. Hodges, P.K.B. (Ed.) Compressibility. In Hydraulic Fluids; Butterworth-Heinemann: Waltham, MA, USA, 1996; pp. 55-66.

21. Mojet, B.L.; Ebbesenz, S.D.; Lefferts, L. Light at the interface: The potential of attenuated total reflection infrared spectroscopy for understanding heterogeneous catalysis in water. Chem. Soc. Rev. 2010, 39, 4643-4655. [CrossRef]

22. Si, Y.; Samulski, E.T. Synthesis of water soluble graphene. Nano Lett. 2008, 8, 1679-1682. [CrossRef]

23. Gao, R.; Hu, N.; Yang, Z.; Zhu, Q.; Chai, J.; Su, Y.; Zhang, L.; Zhang, Y. Paper-like graphene-Ag composite films with enhanced mechanical and electrical properties. Nanoscale Res. Lett. 2013, 8, 32. [CrossRef]

24. Velasco, M.J.; Rubio, J.; Oteo, J.L. Estudio por espectroscopía infrarroja de la reacción de hidrólisis y policondensación del IEOS en presencia de PDMS. Boletín Soc. Española Cerámica Vidr. 2001, 40, 37-42. Available online: http://hdl.handle.net/10261/4760 (accessed on 16 January 2018). [CrossRef]

25. Téllez, L.; Rubio, F.; Peña-Alonso, R.; Rubio, J. Seguimiento por espectroscopia infrarroja (FT-IR) de la copolimerización de TEOS (tetraetilortosilicato) y PDMS (polidimetilsiloxano) en presencia de tbt (tetrabutiltitanio). Boletín Soc. Española Cerámica Vidr. 2004, 43, 883-890. Available online: http://hdl.handle. net/10261/4416 (accessed on 16 January 2018). [CrossRef]

26. Mentlík, V.; Polanský, R.; Prosr, P.; Pihera, J.; Trnka, P. Synthetic ester-based oils and their application in power industry. REEPQJ 2009, 1, 215-219. [CrossRef]

27. Hentschel, K.H. The influence of molecular structure on the frictional behaviour of lubricating fluids. J. Synth. Lubr. 1985, 2, 143-165. [CrossRef]

28. Erhan, S.Z.; Sharma, B.K.; Perez, J.M. Oxidation and low temperature stability of vegetable oil-based lubricants. Ind. Crops Prod. 2006, 24, 292-299. [CrossRef]

(C) 2019 by the authors. Licensee MDPI, Basel, Switzerland. This article is an open access article distributed under the terms and conditions of the Creative Commons Attribution (CC BY) license (http://creativecommons.org/licenses/by/4.0/). 